\title{
Article
}

\section{Critical success factors in implementing an e-rostering system in a healthcare organisation}

Soomro, Zahoor Ahmed, Ahmed, Javed, Muhammad, Raza, Hayes, Dawn and Shah, Mahmood H

Available at http://clok.uclan.ac.uk/21171/

Soomro, Zahoor Ahmed, Ahmed, Javed, Muhammad, Raza, Hayes, Dawn and Shah, Mahmood H (2018) Critical success factors in implementing an erostering system in a healthcare organisation. Health Services Management Research, 31 (3). pp. 130-137. ISSN 0951-4848

It is advisable to refer to the publisher's version if you intend to cite from the work. http://dx.doi.org/10.1177/0951484817745695

For more information about UCLan's research in this area go to http://www.uclan.ac.uk/researchgroups/ and search for <name of research Group>.

For information about Research generally at UCLan please go to http://www.uclan.ac.uk/research/

All outputs in CLoK are protected by Intellectual Property Rights law, including Copyright law. Copyright, IPR and Moral Rights for the works on this site are retained by the individual authors and/or other copyright owners. Terms and conditions for use of this material are defined in the policies page.

\section{CLoK}

Central Lancashire online Knowledge www.clok.uclan.ac.uk

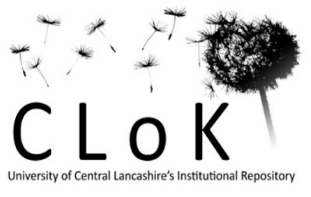


Critical Success Factors in Implementing an E-Rostering System in a

\section{Healthcare Organisation}

\section{Authors}

\section{Zahoor Ahmed Soomro}

University of Central Lancashire, UK

zasoomro@uclan.ac.uk

zahoorahmedsoomro@gmail.com

Cell: +44 7450935544

\section{Javed Ahmed}

University of Central Lancashire, UK

Jahmed1@uclan.ac.uk

\section{Raza Muhammad}

University of Central Lancashire, UK

rmuhammad@uclan.ac.uk

\section{Dawn Hayes}

University of Central Lancashire, UK

dhayes@uclan.ac.uk

\section{Dr: Mahmood H. Shah}

Coventry University, Coventry, UK

Ac3559@conventry.ac.uk 


\section{$\underline{\text { Abstract }}$}

EEffective and efficient staff scheduling has always been a problemchallenging issue, especially in health service organisations. Both the extremes of staff shortage and overage have an adverse impact on the performance of healtheare organisations. In this case, aAn electronic and systematic staff scheduling (e-rostering) system is the often seen as a bestgood solution. However, unless an organisation has an effective implementation implements of such a system effectively, possible cost savingsefficiency benefits could be minimal.

-This study is aimed to research key success factors for the successful-effective implementation of an electronic rostering system,-especially at healthcare organisations. A case study research method was used to evaluate $\underline{\text { Ceritical }} \underline{\text { Ssuccess }} \underline{\text { Ffactors }(\mathrm{CSF})}$ for effectively implementing an e-rostering system. The data was collected through interviews and observations. The findings indicate that technical support, an effective policy, leadership, clear goals and objectives, gradual change, evidence of the advantages of the new system, senior management support ${ }_{2}$ and effective communication are the eritical success factors $\underline{\mathrm{CSF}}$ in implementing an e-rostering system in healthcare organisations. Prior to this study, no such factors were grounded in the current context, 
rostering system in the healthcare sector. _This research also suggests future studies in

different cultures and contexts.

Keywords: Electronic rostering, critical success factors, system implementation, healthcare management and barriers to change, staff management,

\section{Introduction}

The use of computer-based information systems has many advantages including quicker processing and cost_-effectiveness. The health sector, especially National Health Service (NHS) Trusts in UK, have reported significant budget deficits, with nearly half of the total budget being spent on staff payments ${ }^{2}$, so there is a need to effectively utilise staffing systems-- to minimise the usage of agency staff ${ }^{1}$. Manual staff nurse rotation systems in the National Health Service (NHS),NHS, UK have led to overstaffing in some shifts and understaffing in others, which can lead to additional temporary staff resource being required to meet demand. The NHS is currently paying large sums annually to temporary staff as a result of rostering problems. Appleby, ${ }^{2}$ reports that staff cests account for nearly half of the NHS budget. In this regard, Dunn, et al., ${ }^{1}$ and Sprinks, ${ }^{3}$ suggest control over staff budgets, especially in regard to agency staff. E-rostering systems are an effective way to manage staff shifts efficiently, so the Medic Trust decided to implement an erostering system throughout the Medic Trust hospitals. However Iin-depth research in this area, however, has not been carried outdone. The core purpose of the project was to 
implementation phase of any project is critical to its success; this study aims to determine the eritical success factors $\underline{\mathrm{CSF}}$ in the successful implementation of an erostering system in a healthcare setting.

A qualitative case study research approach was adopted and therefore ${ }_{2}$ semi-structured interviews and personal observation were used for data collection. Fifteen interviews were conducted with different respondents. Most of the respondents were the end-users of the new system, including ward managers, deputy ward managers, and staff nurses. One of the researchers was directly involved in the implementation process and therefore provided input from their personal observations. For practitioners, this study will inform them of the critical stccess factors in effectively implementing the e-rostering system in health setting.

\section{Research problem}

Prior to the implementation of the e-rostering system, the ward managers at Medic TrustWWW produced staff rosters on paper. The manual rostering system allowed the ward managers to allocate unlimited shifts according to staff request and the work shift patterns that they preferred, however ${ }_{2}$ the e-rostering system would prevent this from happening.-- The new electronic system would require the managers to follow the rules and procedures to create a staff roster.-- The system would also require agreed templates to be in place within the system that will need to be in line with Trust policy._-_The ward Ward managers have the responsibility for 
help in providing the services smoothlywhich result in the smooth running of services. If a ward manager ignores the system rules and assigns shifts that accommodate staff requests, this could leave mandatory shifts vacant which would require a temporary nursing cover. The Department of Health's report was based on the fact that NHS Trusts were not efficiently controlling the expenditure on the temporary nursing cover. Therefore, to overcome the deficiencies of a manual rostering system, the case organisation introduced an e-rostering system. With the introduction of the e-rostering system, there was a big challenge regarding successful implementation of the system. Se thisTherefore, this research tries to address the question; what are the critical success factors in implementing an e-rostering, system,? Aand how do these factors affect the success of implementing the processsystem?-Before the empirical results this study reviews the existing literature to answer the research questions.

\section{Literature Review}

Along with service quality as a vital focus, healthcare organisations also-pursue cost effectiveness as an important organisational goal. Technology is becoming a key enabler for healthcare organisations to attain these goals but there are certain challenges in the adoption of new technologies related to change management ${ }^{4}$. Introducing a new e-

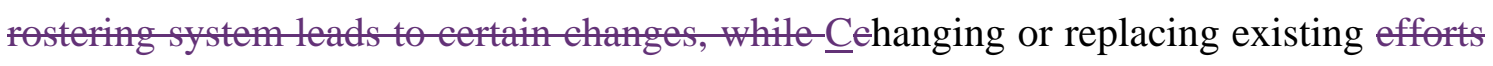
and practices may not beis often not easy ${ }_{2}{ }^{567}$. As a result Therefore, management need to adopt strategies to overcome such challenges to implement changes ${ }^{8}$. For effective 
strategies, management needs to be aware of key factors that lead to success in change management and these are often referred to as eritical success factors $\underline{\text { CSFs. }}$.

Critical Success Factors (CSFs), as as describedproposed by Rockart ${ }_{2}$, are a guiding approach for managers to define information needs in order to reach the goals of the organisation. Regarding CSF methodology, Boynton and $\mathrm{Zmud}^{10}$ state that "The CSF methodology is a procedure that attempts to make explicit those few key areas that dictate managerial or organizational success." Boynton and $\mathrm{Zmud}^{10}$ typically place emphasis on specific areas and actions which are critical to the success of specific programmes and change management. At the moment, literature has many studies focusing on CSF $\underline{s}$ in various fields and contexts. In each field, certain CSF $\underline{s}$ are recommended under which success is likely to occur.

As part of a case study research on technology adoption in healtheare organisations in Thailand, Suebsin and Gerdsri ${ }^{4}$-suggest a list of CSFs. (see Table I). E-rostering system adoption and implementation stages are affected by human-related issues irrespective of the nature of the organisation, so resistance at earlier stages can be reduced by effective change management practices like such as policy enforcement, communication, training and evaluation ${ }^{4}$.-_Paschou, et al., ${ }^{11}$ have a good insight into the issues of e-rostering systems. They studied the characteristics required in an effective e-rostering system but 
worked in a mathematical context and provided mathematical modelling for an effective e-rostering system for health organisations. Table I is a summaery of literature oin CSFS өfwith regards to area of healthcare systems-area.

Table 1. Summary of the key literature related to Critical Success Factors frem

\section{Literature Review-in healthcare systems}

\begin{tabular}{|c|c|c|}
\hline Source & $\begin{array}{l}\text { Description of Authors } \\
\text { Work }\end{array}$ & Critical Success Factors \\
\hline $\begin{array}{l}\text { Ovretveit, } \\
\text { et al., }{ }^{12} \text {. }\end{array}$ & $\begin{array}{l}\text { Improving quality through } \\
\text { effective implementation } \\
\text { of information technology } \\
\text { in healthcare }\end{array}$ & $\begin{array}{l}\text { 1. Ease of navigation } \\
\text { 2. Efficiency in use and accessibility } \\
\text { 3. Physician acceptance } \\
\text { 4. Implementer's responsiveness to concerns } \\
\text { 5. Absence of system failures } \\
\text { 6. No conflicting suitability } \\
\text { 7. Implementation process } \\
\text { 8. User involvement } \\
\text { 9. Education and awareness } \\
\text { 10. Previous computer experience } \\
\text { 11. Strong management support } \\
\text { 12. Adequate people and financial resources } \\
\text { 13. Culture and climate- }\end{array}$ \\
\hline Helfert, ${ }^{13}$ & $\begin{array}{l}\text { Challenges of business } \\
\text { processes } \\
\text { management in healtheare } \\
\text { experience-in the Irish } \\
\text { healthcare sector }\end{array}$ & $\begin{array}{l}\text { Factors affecting HRIS adoption } \\
\text { 1. Technologicaly factors } \\
\text { a) Applications and characteristics } \\
\text { b) Status quøLegacy systems } \\
\text { c) Integration/alignment } \\
\text { d) Preject } \\
\text { 3.2. Organisational factors } \\
\text { a) Demographic } \\
\text { b)-Knowledge and skills } \\
\text { c)-Organisational policies and practices } \\
\text { d)-Resources } \\
\text { 4.3. People factors } \\
\text { a) Attitude/beliefs } \\
\text { b) Communication } \\
\text { c) Support and commitment } \\
\text { d) Training }\end{array}$ \\
\hline $\begin{array}{l}\text { Suebsin and } \\
\text { Gerdsri, }{ }^{4}\end{array}$ & $\begin{array}{l}\text { The analysis of key factors } \\
\text { affecting the success of }\end{array}$ & $\begin{array}{l}\text { 1. Management involvement and support } \\
\text { 2. Change management process }\end{array}$ \\
\hline
\end{tabular}




\begin{tabular}{|l|l|l|}
\hline & technology adoption in & 3. Availability and capability of IT personnel \\
& healthcare organizations in & 4. Vender experience \\
& Thailand & 5. Change agent \\
& 6. Organisational attitude towards change \\
& 7. Supporting technology \\
& 8. Patient safety concern \\
& 9. Work employment and autonomy \\
& 10. Perceived benefits- \\
\hline
\end{tabular}

Table 1 mentions the CSFs for the implementation of information technology in health sector organisations. The research by Ovretveit, et al., ${ }^{12}$ is a good insight into CSFs for implementation of information technology in healthcare. They suggested thirteen factors that have played a critical role in the implementation of electronic medical record (EMR) technology.

Nonetheless, there may be a few similarities in the implementation of the projects such as efficiency in use and access, an absence of system failure, education and awareness and implementation process, which are common to in the implementation of any information technology. But the nature and implications of both projects vary as EMR is related to patient information while e-rostering is related to staff and their scheduling, therefore the CSFs of implementing EMR may not be same for an e-rostering system implementation; as a result, outcomes of this research are novel as no such study has been carried out previously. Helfert ${ }^{13}$ has considered the standardisation of healthcare human resources and payroll in Ireland. He devised technological, organisational and human factors affecting the implementation of healthcare human resources and payroll 
management systems. This was a national level study involving a variety of staff involved in healthcare, whereas the current study focuses only on nursing staff, so the size of the organisation, the nature of the staff under study and the objectives of both studies have differences.

-The study by Suebsin and Gerdsri ${ }^{4}$ also includes a number of CSFs in the adoption of ERP systems in healthcare organisations in Thailand. They suggested ten CSFs (see Table I1), in the adoption of a new enterprise resource planning (ERP) system to order medicines from the supplier. Although these factors are significant for the adoption of technology related to ERP, the nature of the technology in the current study is different and therefore will have varying success factors. So far, the extant literature has no such study devising the CSFs in the implementation of e-rostering systems in the healthcare context. Therefore, this study will helps to bridge this_gap in existing research. gap by suggesting the appropriate CSFs accordingly.

\subsection{Research Methods}

This research is aimed at identifying the CSFs in the successful implementation of erostering systems in an NHS Trust. The case study approach was adopted using semistructured interviews and personal observations were also used as one of the researchers was directly involved in the process of e-rostering system implementation. 


\subsection{The Case Study_Medic Trust}

For the purpose of this research, the case study explores the CSFs in the implementation of the e-rostering system at a healthcare organisation which is $\underline{\text { has been named as Medic }}$ Trust (aA code name given to preserve the confidentiality of the participating organisation).Wrightington, Wigan and Leigh NHS Trust (WWL).__The Case study approach helps to investigate in-depth insights relating to issues in a real--world setting ${ }^{14}$ and explains the elements behind management actions. It also reveals the organisational culture and human resource utilisation, and provides information about the activities, culture $_{2}$ and norms of the organisation ${ }^{15}$. According to Gibbert, et al., ${ }^{16}$ case studies are carried out in close interaction with practitioners who deal with managerial situations because this approach is suited to informing managerially relevant knowledge. The major factor in choosing this organisation wasis the direct involvement of one of the researchers in the implementation phase of the system which helped in the collection of data through participant observation and also provided easy access to the respondents.

The semi-structured interviews were conducted with end users of the system and a total of 15 participants were interviewed. A semi-structured questionnaire was developed and refined to make the data reliable. The principal purpose of the interviews was to getain insight into the system implementation process and highlight the eritical success 
factorsCSFs. The questionnaire contained basic questions on the impact of the system, the potential resistances, motivators ${ }_{2}$ and policy and compliance. Further in-depth questions were asked relating to the roles of the interviewees. With respect to nurses, additional questions were asked related to their knowledge on the functionality of the system, fear of using the system and the benefits of the system. The end-users were further engaged regarding the ease of use, training, support and potential obstacles in the implementation. The managers were further asked about the benefits of the system, control arrangements in the new system, policy compliance obstacles and countermeasures, other potential obstacles and the role of management in the effective implementation of the system.

The participants were randomly chosen to include the respondents involved in the implementation phase and were the core end-users of the system.--The participants also included the ward manager and the deputy ward managers, as they are the main end users of the system. An interview was also conducted with a Matron to gain the views of senior management as they approve the work of the ward managers.-_To get a valid-multidimensional result from this exercise, staff from different directorates in the organisation were invited for participation.___ All the participants were contacted personally, by telephone and through email, to get their prior consent. The participants were briefed about the project and process $_{2}$ and a consent form was signed by the participants 
accordingly. The interviews were conducted after the successful implementation of the project; therefore, the outcomes of the project were apparent and the interviewees deemed it as a successful project. The interviews were recorded through an audio recording tool and were stored and transcribed in full privacy. For participants' privacy purposes, personal questions related to their names and other identifications were not included in the questionnaire. For the most part, questions related to the barriers and CSFs in the adoption and implementation of the system.

One of the authors had held a post as a Rostering Administration Manager, prior to the old system being rolled out. Training on how to administrate the system and how to train the end-users was given to this author. The project team, along with one of the authors, included two other Rostering Administration Managers and a Project Manager.--The plan we were to follow was to implement the system initially across five wards, and then the month after ${ }_{2}$-we_extended the system to another months, the system was extended to batches of two to three wards a month until fully implemented in all the nursing areas at the Trust.-_The experiences that the author had throughout the period as an implementation team member gave her them valuable insight into the system implementation process.-on a first hand basis, whereby the author had observed many different situations. 
Personal biasedness or subjectivity is a critical issue in case study data collection using participant observation. To minimise the possible personal biasedness and to enhance the methodological rigour, suggestions by Iacono, et al., ${ }^{17}$ were acted upon. The suggestion included: a) let the facts speak for themselves: ${ }_{2}$, b) analyse the evidence objectively through more than one source of data; and c) distinguish as appropriate, facts from personal reflections. Thus, the methodological rigour was achieved and personal biasness was minimised using these techniques.

The qualitative data was analysed with the help of NVivo software which helped to classify and code the data accordingly into the nodes. A thematic analysis approach was adopted and eritical suceess factorsCSFs were inferred from the data as themes. Interview text was thoroughly reviewed to infer any CSF $\underline{s}$, and statements that referred to the same factor were categorised into the same node. Finally, a list of all CSFs mentioned in the interviews was developed for discussion.

\section{Results and Discussions}

The Medic TrustWrightington, Wigan and Leigh NHS Trust (referred as WWL) chose to implement an electronic rostering (e-rostering) system following the research carried out by the Department of Health $\underline{(\mathrm{DH})}$.-- In 2005, the department of healthDH had concerns that NHS Trusts were failing to control their expenditure on temporary nursing staff 
effectively.--_The National Audit Office ${ }^{18}$ (NAO) found that $£ 8.3$ billion wereas spent on nursing staff between period 2004 - 2005 and $£ 790$ million wereas spent on the temporary nursing cover.-- The report stated that one of the ways to improve the use of temporary nursing cover was to introduce more effective staff rostering which could result in savings of between $£ 25$ and $£ 50$ million for the NHS. Therefore, the Medic TrustWWL decided to implement an e-rostering system at their hospitals and this study is designed to investigate the CSFs in the implementation of the project.

The Medic TrustWWL purchased the e-rostering system (called Health-Roster) from Manpower Software PLCple. The system was purchased in 2008 and was fully implemented in 2009; it took about twelve months_to carry out the full implementation. Once fully implemented, ninety-three nursing wards and units became live on the Health Roster system.-- Prior to the e-rostering system, staff rosters were produced manually on paper.-- The e-rostering system helped to improve the productivity of the NHS workforce and aided effective healthcare.- The Medic TrsustWWL stated key objectives of the system such as the achievement of potential savings, placing less dependency on agency nurses and having a transparent rostering system. It was imperative that the system was fully utilised to achieve these objectives, requiring staff to adopt the system and take into account the skills and knowledge they had been given during the initial training on how to use the system. 
At the outset, motivational factors, such as encouraging acceptance of the system, was observed, which paved the way for the initial success ofat the implementation phase. The other factors that made the implementation successful were technical support, committed leadership, having evidence of the advantages of the new system, clear goals and objectives, gradual change, senior management support, effective communication and monitoring and reporting.

\subsection{Policy and Compliance}

Having a rostering policy in place that staff adhere to was an objective that the Trust measured the success of with respect to the implementation of the system. Observations during the implementation phase highlighted the fact that with a manual rostering system, nursing wards were not following the Ppoliciesy and procedures strictly.--In that situation, the-ward managers were creating rosters to satisfy the staff rather than actual demand. The monitoring of the manual rosters was also difficult and time consuming, which sometimes resulted in overstaffing in less busy times and understaffing in busy hours. This was the basic reason for increased wage expenses and dependency on agency nurses, which also affected the quality of service. 
Although the staff were clear on the policy regarding the rostering system-but ${ }_{2}$ lack of compliance was a major obstacle to achieve the objectives. In the e-rostering system, compliance monitoring became easiery, which motivated the rostering staff to fully comply with it. So detailing a policy and having an easy compliance monitoring process are eritical success factors $\underline{\mathrm{CSF}}$ in the implementation of the e-rostering system. Siponen, et al., ${ }^{19}$ also supports the notion that a policy and its compliance has a positive impact on the behaviour of employees.

\subsection{Technical Support}

It was observed during the training sessions that end users found the system difficult on the account of close monitoring of the system to ensure the-compliance with rostering policy. Therefore, the project team spent more time in supporting the end users to help and motivate them to overcome this issue, which proved to be helpful in complying with the rostering policy. Regarding the support received, a ward manager also mentioned that,

"The e-rostering team from the start have been fantastic._- The team is always available and the service has been excellent and in my opinion that is why this has been successful”.

It was therefore evident that the technical support received from the project team helped the rostering managers in the effective compliance of the policy. Thus, the project team's 
technical support became a success factor for the effective implementation of the erostering system.

\subsection{Leadership}

The leadership of the project has a significant impact on the successful implementation of the e-rostering system ${ }^{20}$. The project leaders had a clear vision, which gave inspiration to the staff. The project leaders also motivated the end users and related staff- through effective communication, which turned the barriers into success factors. Prompt feedback was given and the efforts of the staff were valued towards the accomplishment of the project, which also encouraged the end users to strive towards the achievement of the project objectives. So it can be argued that effective leadership has a significant impact on project implementation.

\subsection{Clear Goals and Objectives}

At the initial stage, ward managers were confused with the new system, however during the training sessions, they were provided with the goals and objectives of the project and any concerns raised were responded to in a satisfactory manner. Once the ward managers were clear about the goals and objectives of the project, their intentions focused towards the achievement of these. Such a notion is also supported by Costantino, et al., ${ }^{21}$ and Mathrani \& Viehland ${ }^{22}$, who argue that clarity on project goals and objectives are 
essential ingredients for achieving the benefits and the overall success of projects. Consequently, clarity in goals and objectives of the project proved to be a eritical success factor $\underline{\mathrm{CSF}}$ for the project $^{23-25}$.

\section{5___ Gradual Change}

During the interviews, all the participants agreed that the implementation schedule was gradual and they had experienced no material issues as the project was implemented according to a pre-planned schedule ${ }^{21,26}$. Initially, the manual rostering processes were carried out in parallel to the electronic system and once end users, managers and matrons were satisfied with the accuracy of the system, the manual processes were no longer carried out. On the other hand, the system was implemented in phases, five wards a month. Regarding this implementation strategy, a ward manger stated that:

"The system could have failed if it was to be implemented suddenly throughout the Trust”.

So, the gradual implementation phase helped the end users and other stakeholders to understand the project, not only with help from the project team- but also from colleagues in other wards who had experience of the system. So gradual change became significant to the successful embedding of the system, as too much haste at the implementation stage may well have led to pre-mature results and project failure 22,27 . 


\subsection{Having Evidence of the Advantages of the New System}

As already mentioned, the manual rostering system processes were carried out in parallel to the e-rostering system. The advantages of the new system such as; time and cost saving, effectiveness and efficiency, close monitoring, easy compliance of the rostering policy and accuracy of the system motivated the staff and the managers in terms of the effective implementation of the e-rostering system. In this regard ${ }_{2 \Sigma}$ one; of the ward managers mentioned that:

"I actually thought that paper was more flexible, but e-rostering makes you put the times in, accurately".

The statement shows that the staff realised the advantages of the new system, which was a motivation factor for the successful implementation of the system. Thus, evidence of the advantages of the new system became a eritical success factorCSF in the effective implementation of the system.

\subsection{Senior Management Support}

Support from senior management helped in making the project implementation possible ${ }^{22,23}$. The senior managers provided guidance, resources, and feedback to the field managers ${ }^{28}$ while the project team helped with troubleshooting. Regarding the support 
received from senior and project managers, staff confirmed that it was motivating to adopt the new system.a matron stated that:

"The e rostering team from the start have been fantastic. The team is always available and the service has been excellent and in my opinion, that is why this has been successful". Thus In light of this, management support proved to be a factor for success in the erostering system implementation. Management support is also considered critical in project implementation in various other studies such as; Anjum, et al., ${ }^{29}$ - Bhatti, ${ }^{30}$ Costantino, et al., ${ }^{21}$ Garg \& Agarwal, ${ }^{26}$ Mathrani \& Viehland ${ }^{22}$ _and Ravesteyn \& Baterburg $^{31}$.

\subsection{Effective Communication}

A strong communication link between all levels of staff proved helpful in overcoming resistance. Such results also validate the argument of Mullins ${ }^{32}$ that effective communication at all levels is a better tool to overcome the resistance to change. With effective communication, the Medic TrustWWL increased the acceptance level of the end users and ward managers, which in result motivated them with regards to successful implementation. So effective communication has a critical role in the successful implementation of projects $26,27,30,31$.

\subsection{Monitoring and reporting}


Monitoring and reporting are critical aspects to keep the activities of employees aligned

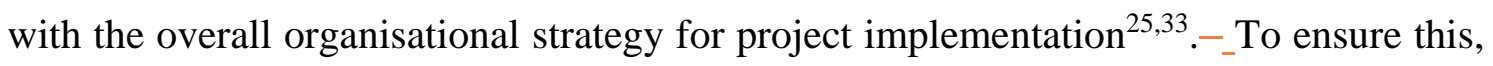
the supervising staff had responsibility for close monitoring and reporting, in order to address any problem in time and to ensure the successful implementation of the project. So the strategy of close monitoring and reporting played a critical role in successful implementation of the e-rostering system at the Medic TrustWWL. The results of the identification of eritical success factors $\underline{\mathrm{CSFS}}$ at the Medic TrustWWL, construed from the observations and interviews, have been summarised in Table 2.

Table 2 Summary of the Research results with reported data collection method.

\begin{tabular}{|l|l|}
\hline Data Collection Method & Critical Success Factors \\
\hline Observations & $\begin{array}{l}\text { 1. Senior management support- } \\
\text { 2. Rostering policy and compliance- } \\
\text { 3. Technical support }\end{array}$ \\
\hline Interviews & $\begin{array}{l}\text { 1. Leadership } \\
\text { 2. Clear goals and objectives } \\
\text { 3. Gradual çehange } \\
\text { 4. Effective communication } \\
\end{array}$ \\
& 6. Monitoring and reporting \\
\hline
\end{tabular}


7. Having $\underline{\text { eEvidence of the aAdvantages of the } \underline{n} \mathrm{New}}$ sSystem

The observational research was significant as resistance was witnessed on a first-hand basis during the training sessions. End users training sessions helped them overcome this resistance and fear of the unknown. Ward managers, deputy ward managers, and nurses were the end users of the system, so they were given-provided training, but the matrons (their supervisors) were not provided with such training which created problems in the approval of rosters produced by the end users on the system. In this instance, support from senior management helped matrons and end users deal with any issues faced. The existence of the related policy and technical support was also a critical factor motivating the adoption of the e-rostering system.-- The interviews revealed similar barriers, but also added more success factors. The respondents stated thate effective leadership, clear objectives $_{2}$ and gradual change was helpful in the effective implementation of the system. The respondents also revealed that effective communication, monitoring $g_{2}$ and senior management support were also critical to this.

Along with the support for CSFs from many authors, there are also some criticisms. For example Berg $^{34}$ is of the view that the same factors and management strategies that were successful in one organisation may not be similarly successful in other organisation. 
$\operatorname{Berg}^{34}$ further argues that different organisations with varying sizes, different leadership and management styles, different cultures, different financial situations and different environments may react differently with similar technological innovations or to similar implementation strategies. So, for effective implementation, organisational and environmental aspects should be considered and certain changes must be made in respect of implementation policies and strategies to best fit with organisational factors.

\subsection{Conclusions}

Staff scheduling has always been a critical problem, especially in healthcare organisations, as an overage or shortage of nursing staff adversely affects the objectives of healthcare organisations. In the absence of an e-rostering system, the Medic Trust-WWWE was spending heavily on the temporary nursing cover. Implementation of information technology, especially at healthcare organisations, has always been a critical issue in terms of adoption and implementation ${ }^{5-7}$. So far, this study was aimed at exploring the eritical success factors $\underline{\mathrm{CSFS}}$ for successful implementation of the e-rostering system at the Medic TrustWWLE. The eritical suceess factorsCSFs for effective implementation were investigated and analysed in detail to discern their impact on the implementation process of e-rostering systems in health sector organisations.

For data collection, a case study method was adopted, and a qualitative approach was utilised to gain an in-depth insight into the facts.- In our qualitative approach with respect 
to data collection, semi-structured interviews were conducted with 15 members of staff concerned with the project implementation. Personal observations were also part of data collection as one of the researchers was personally involved in the project implementation.

This study explores some key factors which were critical for the implementation of the erostering system at a healthcare organisation. These include senior management support, technical support, effective leadership, clear goals and objectives, gradual change, effective communication and monitoring and reporting. This set of factors has not been explored in the current context, which is the novel contribution of this research. In the real world setting, this study would be helpful to managers for the successful implementation of e-rostering, especially in a healthcare setting.

Like other studies, this study-research also has some limitations. As the study was conducted at an NHS healthcare organisation in the UK, there may cultural differences in other countries which are not addressed here. So it may be possible that studies in countries with different cultures may have different outcomes. Also, this study was limited to an NHS Trust so there may be a possibility of varying results in a private healthcare setting. As mentioned previously, one of the authors was involved in the implementation of the project, so there may be personal biasness in the data in spite of taking measures to minimise itthis. Therefore, the authors suggest future studies with a 
quantitative data collection approach, in different cultures and private healthcare organisations. These eritical success factors $\underline{\mathrm{CSF}}$ can also be analysed for their application in contexts other than healthcare, so future studies will also be helpful in generalising the outcomes of this study. 


\section{References}

1. Dunn P, McKenna H and Murray R. Deficits in the NHS 2016, https://www.kingsfund.org.uk/sites/files/kf/field/field_publication_file/Deficits_i n_the_NHS_Kings_Fund_July_2016_1.pdf.(2016, accessed 18 December 2016)

2. Appleby J, Galea A and Murray R. The NHS productivity challenge. Experience from the front line, https://www.kingsfund.org.uk/sites/files/kf/field/field_publication_file/the-nhsproductivity-challenge-kingsfund-may14.pdf (2014, accessed 18 December 2016)

3. Sprinks J. Lord Carter's model hospitals aim to save the NHS£ 5 billion a year: Can the latest recommendations improve productivity and achieve the predicted savings without compromising nursing care? Jennifer Sprinks reports. Nurs Stand 2016; 30: 12-13.

4. Suebsin C and Gerdsri N. The Analysis of key factors affecting the success of technology adoption in healthcare organizations in Thailand. Technol Manag Emerg http://ieeexplore.ieee.org/xpls/abs_all.jsp?arnumber=6304172 (2012, accessed 7 March 2016).

5. Adler-Milstein J and Bates DW. Paperless healthcare: Progress and challenges of an IT-enabled healthcare system. Bus Horiz 2010; 53: 119-130.

6. Chau P and Hu P. Investigating healthcare professionals' decisions to accept 
telemedicine technology: an empirical test of competing theories. Inf Manag http://www.sciencedirect.com/science/article/pii/S0378720601000982 (2002, accessed 7 March 2016).

7. Tsiknakis M. and Kouroubali A. Organizational factors affecting successful adoption of innovative eHealth services: A case study employing the FITT framework. Int J Med Inform 2009;78: 39-52.

8. Cohn K, Berman J, Chaiken B, et al. Engaging physicians to adopt healthcare information technology. J Healthc Manag 2009; 54: 291-300.

9. Rockart J. Chief executives define their own data needs. Harv Bus Rev 1978; 57: $81-93$

10. Boynton A, Zmud R. An assessment of critical success factors. Sloan Manage Rev 1984; 25:17-27.

11. Paschou M, Papadimitiriou C, Nodarakis N. Enhanced healthcare personnel rostering solution using mobile technologies. J Syst Softw 2015; 100: 44-53.

12. Øvretveit J, Scott T, Rundall T, et al. Improving quality through effective implementation of information technology in healthcare. Int J Qual Health Care 2007; 19: 259-266.

13. Helfert M. Challenges of business processes management in healthcare: Experience in the Irish healthcare sector. Bus Process Manag J 2009;15:937-952.

14. Yin R. Case study research: Design and methods. $5^{\text {th }}$ ed. London: Sage 2013. 
15. Stake R. Multiple case study analysis. London, The Guilford Press 2013.

16. Gibbert M, Ruigrok W, Wicki B. What passes as a rigorous case study? Strateg Manag J 2008; 29: 1465-1474.

17. Iacono J, Brown A, Holtham C. Research methods-A case example of participant observation. Electron J Bus Res methods 2009; 7: 39-46.

18. Office NA.-_Improving the use of temporary nursing staff in NHS acute and foundation trusts. London: National Audit Office, 2006.

19. Siponen M, Mahmood M and Pahnila S. Technical opinion Are employees putting your company at risk by not following information security policies? Commun ACM 2009; 52: 145-147.

20. Kandelousi N. Key success factors for managing projects. WASET_2011; 5: $1514-1545$.

21. Costantino F, Gravio G Di, Nonino F. Project selection in project portfolio management: An artificial neural network model based on critical success factors. Int J Proj Mgt 2015; 33: 1744-1754.

22. Mathrani S, Viehland D. Critical Success Factors for the Transformation Process in Enterprise System Implementation. PACIS_-2010; 821-831.

23. Fortune J, White D, Jugdev K. Looking again at current practice in project management. Int J Manag Proj Bus 2011; 4: 553-572.

24. Nagpal S, Khatri S, Kapur P. Exploratory study to identify critical success factors 
penetration in ERP implementations. In 3rd International conference on Reliability, Infocom, Technologies and Optimisation (Trends and Future Directions)Noida, India, Oct 8-10, 2014.

25. Shatat A. Critical Success Factors in Enterprise Resource Planning (ERP) System Implementation: An Exploratory Study in Oman. Electron J Inf Syst Eval 2015; 18: $36-45$

26. Garg P, Agarwal D. Critical success factors for ERP implementation in a Fortis hospital: an empirical investigation. J Enterp Inf 2014; 27: 402-423.

27. Shen C, Chou C. Business process re-engineering in the logistics industry: a study of implementation, success factors, and performance. Enterp Inf Syst 2010; $4: 61-78$

28. Soomro Z, Shah M, Ahmed J. Information security management needs more holistic approach: A literature review. Int J Inf Mgt 2016; 36: 215-225.

29. Anjum M, Sadiq M, Marwat N. Decisive Success Factors of ERPS Implementation in Pakistani Health Care Industry: A Pragmatic Study. J Inf Proc Mgt 2015;6: 73-82.

30. Bhatti T. Critical Success Factors for the Acquisition of Enterprise Systems: Empirical Validation . In International conference on Information Resources Management, Ho Chi Minh City, Vietnam 2014.

31. Ravesteyn P, Batenburg R. Surveying the critical success factors of BPM- 
systems implementation. Bus Process

Managhttp://www.emeraldinsight.com/doi/abs/10.1108/14637151011049467

(2010, accessed 7 March 2016).

32. Mullins L. Essentials of organisational

behaviourhttps://books.google.co.uk/books?hl=en\&lr=\&id=7J1Zk-nx-

4MC\&oi=fnd\&pg=PR14\&dq=Mullins,+L.+J.+(2008).+Essentials+of+organisati onal+behaviour+Pearson+Education.+\&ots=Ca161n0n3S\&sig=qAdn2QVLiLbM ErH2wTxw_t7XnNw (2008, accessed 7 March 2016).

33. Javadin S, Raei R, Iravani M. Conceptualizing and examining the critical success factors for implementing Islamic banking system towards banking sector of Iran: A mixed method approach. Iran Jhttp://search.proquest.com/openview/3341bf4ed0eafcd3ea250156db52e0c0/1?p q-origsite $=$ gscholar (2015, accessed 7 March 2016).

34. Berg M. Implementing information systems in health care organizations: myths and challenges. Int J Med Informhttp://www.sciencedirect.com/science/article/pii/S1386505601002003 (2001, accessed 7 March 2016). 